\title{
O ENSINO DE GRAMÁTICA EM UMA PERSPECTIVA PLURILÍNGUE
}

\author{
OLIVEIRA, José Adriano de ${ }^{1}$; FERREIRA, Diego Augusto Gonçalves².
}

\section{RESUMO}

Este estudo pretende refletir sobre o ensino e o estudo da gramática no contexto de aprendizagem e de uso. Esta reflexão levanta questões acerca de como a gramática deve ser explorada e refletida diante das inúmeras circunstâncias. O cerne das reflexões é o uso funcional da gramática de modo que a mesma não seja dificuldade para a perfeita fluência da linguagem e da comunicação. Em conjunto com as competências da linguagem, observa-se que a mesma pode desempenhar diversas características de aprendizagem, porém deve-se priorizar a gramática como ferramenta de sofisticação e maturidade em todos os contextos em que os falantes a utilizam. Assim, deseja-se examinar, questionar e refletir os conceitos propostos para que uma nova visão de ensino e de pluralidade linguística aconteça dentro e fora do contexto da sala de aula.

Palavras-chave: Ensino de gramática. Pluralidade. Linguística.

\begin{abstract}
This study aims to reflect on the teaching and study of grammar in the context of learning and use. This reflection raises questions about how grammar should be explored and reflected in the many circumstances. The core of the reflections is the functional use of grammar so that it is not a difficulty for the perfect fluency of language and communication. Together with language competences, it can be observed that it can play several learning characteristics, but grammar should be prioritized as a tool of sophistication and maturity in all contexts in which speakers use it. Thus, we want to examine, question and reflect the proposed concepts so that a new vision of teaching and linguistic plurality happens within and outside the context of the classroom.
\end{abstract}

Keywords: Grammar teaching. Plurality. Linguistics.

\footnotetext{
${ }^{1}$ Graduado em Letras pelo Centro Universitário UNIFAAT. Especialista em Filosofia e ensino de Filosofia no Centro Universitário Clarentiano. Professor da rede pública e privada.

${ }^{2}$ Bacharel em Filosofia pela Faculdade Católica de Pouso Alegre-MG, licenciado em Filosofia pelo Centro Universitário Clarentiano, especialista em Filosofia e Ensino de Filosofia pelo Centro Universitário Clarentiano, e graduando em História pela UNIFAVENI.
} 


\section{Introdução}

Ao se falar sobre o cidadão letrado, há sempre duas concepções: a primeira faz jus ao próprio nome, ou seja, o letrado seria aquele que tem um conhecimento que lhe permite trafegar por vários setores do entendimento e das relações humanas. Para este não será difícil entender o mundo da literatura como um todo, das finanças, da mídia e da comunicação. A segunda paira sobre o sujeito que foi à escola, concluiu sua grade e até mesmo chegou ao nível universitário, porém sua bagagem linguística é restrita e não fomenta maiores ambições dentro do contexto da comunicação; logo esta mesma pessoa estará trafegando em ambientes determinados e que não exigem uma maior exploração da língua e do mundo que a cerca.

Outro fator determinante nesta concepção da linguagem está no seu uso reflexivo, pois uma linguagem que não é ciente daquilo que pensa não exercerá sua função mediante a mensagem proferida, resultando em um entendimento cada vez mais defasado e carente de leitura. Neves (1990, 0. 41), em sua explanação, cita que:

[...] não se observa qualquer reserva de espaço para a reflexão sobre os procedimentos em uso, sobre o modo de relacionamento das unidades da língua, sobre as relações mútuas entre diferentes enunciados, sobre o propósito dos textos, sobre a relação entre os textos e seus produtos e receptores etc.

Ao se entender a manifestação dos signos que compõem a comunicação logo se estabelece uma reflexão sobre aquilo e a mensagem será captada. Nesta perspectiva cabe também entender os vários sentidos envolvidos em determinado enunciado para que o texto transmita sua mensagem e o leitor saiba lê-lo. Ao explorar as evidências colocadas em um meio em que a língua é viva e manipulável, deve-se também cogitar sobre o como e o porquê de tal situação e o que será instigado com isso.

Percebe-se a partir destes aspectos que uma maneira sólida de ensino e entendimento da gramática deve ser avaliada. Gerar falantes capazes de serem poliglotas em seu próprio idioma parte da necessidade de um estudo gramatical bem alicerçado, porém envolto nas inúmeras manifestações da língua como um todo. A dificuldade consta em não estabelecer paralelos entre prescrição das regras e a dinamicidade da língua. Na concepção gramatical de Cegalla (2008, p. 03), observa-se que:

[...] tomamos a liberdade de lembrar aos abnegados colegas de ensino que o estudo da gramática, por parte dos discípulos, deve andar lado a lado com a redação de textos, a interpretação de poemas e excertos literários e a leitura de livros e revistas de boa qualidade. Só com essa didática plurivalente é que o ensino do português atingirá seu 
objetivo precípuo, que é levar o estudante a assenhorar-se gradativamente das normas e dos recursos do idioma, nas modalidades oral e escrita.

O espaço e o tempo destinados ao ensino da língua devem ser entendidos como um tempo de se fazer ciência linguística, ou seja, a língua é viva e dinâmica, conta com um vasto repertório de dialetos e modos de verbalização, embutidos em culturas e maneiras de se viver; deste modo o estudo do principal utensílio da comunicação deve nos transpor de simples exercícios ou teorias frias e calculistas para uma leitura que não se reduza apenas ao texto em si, mas também ao mundo, que pode ser desde aquele em que o mesmo foi produzido ou aquele que o texto pretende produzir, mas que para isto precisa de um leitor capacitado.

A associação tão esperada de um falante que é ao mesmo tempo aprendiz e usuário do idioma passa por uma reformulação do pensamento e da linguagem, que envolve reflexão diante do que é produzido. A grande oportunidade será dada quando deparado com uma circunstância em que se observam os erros comuns da concordância verbal, possa-se fazer gramática, no modo mais natural e profícuo, e isto seja sanado de modo autêntico e original.

Nesta perspectiva, é válido refletir como no fragmento abaixo:

\footnotetext{
Assim se procedia na aula de português: lido o trecho, o estudante, por si só, ou com o auxílio do mestre, procurava explicar-lhe o sentido, para o quê punha na ordem direta as inversões, substituindo os vocábulos por sinônimos, apontando a significação de cada palavra e as acepções em que podia ser tomada, e, uma vez por outra, convertia o verso em prosa (RAMOS, 1924, p. 38).
}

Nota-se, por este trecho, que tais necessidades de uso e compreensão da língua já foram registradas no passado e também novas maneiras de se enfrentar tal cisão já foram vistas. Sendo assim, o presente artigo tem a intenção de despertar no falante, independentemente de sua atuação, a inversão que deve ser feita nos conceitos gramaticais até então firmados, e despertar uma nova visão de linguagem reflexiva e palpável.

\section{Gramática e suas competências}

Umas das maiores inquietações que assombram mestres e estudantes da língua é achar o motivo de se aprender e dominar a gramática. Há uma porcentagem de mestres que excluem tal conteúdo, não por portarem uma filosofia inovadora e capaz de restaurar toda a grade de ensino, mas por sua insuficiência de conteúdo e de reflexão diante de tamanho conteúdo. Deste modo, levantam a bandeira da incoerência do aprendizado gramatical, porém apegando-se aos textos ditos "necessários" e objetivos, e com estes ministram suas aulas, criando uma cadeia de falantes incapazes de dominar o idioma e pobres de significados e leituras. 
Outro grupo que também se utiliza da mesma inquietação nasce justamente de mestres que edificam a linguagem com todas as ferramentas e enriquecem o vasto campo da linguagem, mostrando as diversas potências que há em todo falante e em toda escrita. Não há dúvidas de que assim como o exemplar aprendizado gera discípulos, o incoerente ensino também forma seus agregados. Nestes dois polos, reside a dúvida, mãe de toda ineficiência linguística. Nesta dinâmica, que por muitas vezes perturba a verdadeira identidade linguística, deve-se observar os pontos em que tais brechas inutilizam a arte de se "fazer ciência", dentro e fora da sala de aula, e tornar novas tais atitudes frente ao levante número de falantes inconscientes de sua língua.

A primeira perspectiva norteia-se pelo entendimento científico da linguagem:

\begin{abstract}
O estudo da gramática pode ser um instrumento para exercitar o raciocínio e a observação; pode dar a oportunidade de formular hipóteses; e pode levar à descoberta de fatias dessa admirável e complexa estrutura que é a língua natural. O aluno pode sentir que está participando desse ato de descoberta, através de sua contribuição à discussão, ao argumento, à procura de novos exemplos e contraexemplos cruciais para a testagem de uma hipótese dada (PERINI, 2002, p.31).
\end{abstract}

É notável que o estímulo linguístico deve se nortear por uma reflexão concreta da linguagem. Nesta intenção, haverá sempre uma possibilidade ou mais que o falante, seja ele aluno ou não, verificará no universo da sua comunicação. Tal fator é de tão grande importância, que o entendimento da linguagem como algo vivo, mas que ao mesmo tempo é palpável e histórico, induzirá a uma ativa utilização do idioma, sem mais paradigmas e inquietações.

Na perspectiva de Vygotsky (1989, p. 86), salienta-se que:

[...] o estudo da gramática é de grande importância para o desenvolvimento mental da criança[...]. Ela não pode adquirir novas formas gramaticais ou sintáticas na escola, mas graças ao aprendizado da gramática e da escrita, realmente se torna consciente do que está fazendo e aprende a usar suas habilidades conscientemente.

O uso consciente da linguagem é libertador em todas as esferas da participação humana. Isto implica em uma democratização e maior facilidade no que tange ao entendimento das coisas que fazem a história humana acontecer. Ler os fatos, notar as entrelinhas, refletir sobre questões, formular hipóteses, ouvir e expressar-se através da arte e compreender as intenções da mídia são frutos da consciência linguística que todo nativo deve absorver.

Nestas duas questões é muito importante notar que tais elementos levam o falante a se tornar responsável por sua própria linguagem, ou seja, ele não será apenas um número, mas um membro atuante dentro da comunidade pertencente. A produção linguística em todos os âmbitos 
e a própria produção intelectual, que varia desde uma escrita acadêmica até um comentário útil em um determinado site, serão plenas e atingirão seu objetivo, uma vez que a linguagem será apreendida de forma múltipla e realista.

O ensino e a aprendizagem da gramática não podem ser algo independente da linguagem. O modelo seguido não corresponde aos anseios da necessidade humana e dispersa a cientificidade produzida pela língua. Para o grande linguista italiano Lo Cascio (1978, p. 34), a gramática deve ir além da regra:

[...] uma gramática descritiva destinada ao ensino da língua materna deverá ter como objetivo explicitar ao aluno o sistema linguístico que ele já conhece e especialmente fazê-lo entender que a língua, além de ser um veículo de expressão e criatividade, é também instrumento de comunicação, é instrumento social e que por isso se organiza segundo as funções que deve cobrir.

Deste modo, observa-se que o ensino da gramática é responsável pela produção da comunicação na sociedade e deve ancorar-se em métodos e leituras profundas das produções que compõem o território comunicativo.

Não se pode pensar em um falante com um fundo determinista, radicado em uma aprendizagem direcionada para apenas uma função. O verdadeiro preparo linguístico parte de uma noção que abre o leque das diversas opções e questões que norteiam a linguagem do contexto em que se produz. É preciso ser um poliglota em seu próprio idioma, "porque o que em geral ocorre é que todo falante, dentro de sua língua histórica, é 'plurilíngue' ou 'poliglota', isto é, [...] consegue distinguir 'desvios'”' (BECHARA, 1985, p. 55).

Para que o aluno e falante possa conhecer e reconhecer as múltiplas facetas da linguagem, é indispensável fornecer uma bagagem embebida de circunstâncias que promovam a independência linguística, mas com caráter científico e lógico. A construção de situações deve mostrar de forma diligente a utilidade linguística consciente e clara. Isto não significa dizer que se na ocasião “a” pede-se um linguajar menos rebuscado, o falante deixará de usar os conceitos básicos de sua língua, uma vez que julga necessário usá-los apenas na ocasião "b”, em que se exija tal eficácia. Saber nortear-se por uma unicidade linguística, levando em conta a potência da mensagem, deve sempre sobrepor-se às defasagens e interrupções que porventura surjam e disponham brechas para que a ciência linguística não aconteça.

Na visão de Vieira (2013, p.101), tal realidade vivifica esta ciência, pois

[...] a partir dos objetivos centrais do ensino de Língua Portuguesa, deve-se promover o raciocínio-científico do aluno, com base em atividades reflexivas, para que ele 
desenvolva o conhecimento[...], de modo a fazer opções linguísticas conscientes na produção de textos orais e escritos.

A atitude linguística, quando formulada em bases que promovam a comunicação como um todo, dificilmente deixará de ser uma atitude científica, pois a consciência linguística por si mesma desempenha tal função. A capacidade plurilíngue de um sujeito parte de novas e diversas maneiras de entender a circunstância em que o código linguístico seja lido e entendido.

A maneira de decodificar os códigos que foram formulados por um falante é uma ciência, porém que terá seu objetivo concretizado a partir do outro que também participa e ainda decodifica estes mesmos códigos. Na visão de Travaglia (2002, p. 23),

[...] a dinâmica comunicativa dessa concepção de linguagem se dá por meio da relação entre o falante e o ouvinte, quando o falante tem em sua mente ideias a transmitir a seu interlocutor.

O redirecionamento do estudo gramatical, em uma perspectiva contextualizada, contribuirá para uma unificação semântica, que engloba a mensagem e o meio pelo qual ela circula e se concretiza. A consciência gramatical dentro do texto deve surgir sempre que o falante questionar tal necessidade.

\begin{abstract}
Saber gramática, ou mesmo saber português, é geralmente considerado privilégio de poucos. Raras pessoas se atrevem a dizer que conhecem a língua. Tendemos a achar, em vez, que falamos 'de qualquer jeito', sem regras definidas. [...] Vou sustentar que, apesar das crenças populares, sabemos, e muito bem, a nossa língua[...] nosso conhecimento da língua é ao mesmo tempo altamente complexo, incrivelmente exato e extremamente seguro. [...] Mesmo pessoas que nunca estudaram gramática chegam a um conhecimento implícito perfeitamente adequado da língua. São como pessoas que não conhecem a anatomia e a fisiologia das pernas, mas que andam, dançam, nadam e pedalam sem problemas (PERINI, 2000, p.11).
\end{abstract}

Como dito anteriormente, o movimento que a concepção e a recepção gramatical devem fazer é justamente o de provocar-nos perante a diversidade linguística que produzimos e recebemos. O despertar desta consciência deve surgir não como algo jamais visto, mas como um objeto tocado e conhecido por todos desde os primeiros atos de fala.

\title{
3 Ensinar gramática ou análise linguística?
}

Nem uma nem outra, mas ambas. Esta certeza deve ser a inspiração para todo o mestre da língua que pretende formar falantes capazes de compreender as múltiplas facetas de um idioma e jamais estar submisso a apenas uma maneira de ser ou de ler as coisas. Assim, ensinar 
gramática incorrerá originalmente em ensinar análise textual, ou seja, se o professor compreende e domina a unificação de ambas, logo saberá que uma será indispensável à outra.

A perspectiva do ensino da gramática de forma unificada se origina de como é entendida tal didática, pois uma vez que a língua necessita de uma dinamicidade para acontecer e fazerse concreta, logo o seu estudo deve estar associado ao objetivo da construção textual; na visão de Antunes (2007, p. 34) "um sistema abstrato, virtual apenas, despregado dos contextos de uso, sem pés e sem face, sem vida e sem alma, 'inodora, insípida e incolor', os resultados não serão satisfatórios".

A associação das duas concepções de ensino de linguagem permite uma inovadora capacidade linguística aos falantes porque gera contribuições contextualizadas e reflexivas. $\mathrm{O}$ ato de refletir e transmitir tal pensamento acerca daquilo que constitui a língua permite ao falante não se tornar "joguete” nas diversas opiniões já cristalizadas.

A possibilidade de teorizar aquilo que já foi observado e usado será a forma mais real possível de ver a junção destas duas percepções. Ao colhermos um determinado texto, seja ele de qualquer gênero, a possibilidade de uma afeição direta e conhecida de tal manifestação será notada pelo leitor em um primeiro momento. $\mathrm{O}$ aprendiz, o falante e o aluno não formularão nenhuma teoria ou não irão manifestar nenhum engajamento sem antes experimentar e ver sentido naquilo que é exposto.

Para Travaglia (2011, p.136),

[...] é uma atividade em que o aluno, a partir de dados linguísticos [...], vai buscar criar, formular uma teoria que descreva e/ou explique os fatos sob a observação, o que, no mínimo, vai ampliar sua visão dos fatos da língua, libertando-o de uma "viseira" que muitas vezes condiciona uma interpretação unívoca de uma realidade múltipla.

Lidar com a manifestação linguística exige bagagem e intuição. Os vários meios midiáticos que caracterizam este nosso século promovem diversas formas de formação e informação. Neste sentido, não é novidade notar que há entrelinhas que carregam gigantescas intuições, seja para finalidades específicas ou não. O texto, como principal identidade e manifestação destes meios, carregará consigo todas as circunstâncias que determinado contexto queira promover e enfatizar. Nesta perspectiva, um emprego verbal com determinada ênfase será entendido por mais de uma maneira, e uma delas engloba a presença do verbo e qual sua finalidade em determinada ocasião. 
Em relação ao critério gramatical do verbo, esta definição será entendida como algo necessário na construção de um período, porém em um contexto semântico ele incutirá intenções, de acordo com a sua forma nominal e o tempo em que foi empregado. Ao ser observado nestas duas condições, o leitor entenderá sua finalidade e como será indispensável entendê-lo de modo completo e dinâmico para que a mensagem faça sentido.

A análise linguística presente na produção textual deve envolver toda a atuação de escrita e de formas de produção. Neste sentido o falante deverá apropriar-se e perceber o quanto tais dimensões podem e devem contribuir em sua eficácia linguística. Segundo os Parâmetros Curriculares Nacionais é preciso que o aluno

[...] constitua um conjunto de conhecimentos sobre o funcionamento da linguagem e
sobre o sistema linguístico relevantes para as práticas de escuta, leitura e produção de
textos; aproprie-se dos instrumentos de natureza procedimental e conceitual
necessários para a análise e reflexão linguística (delimitação e identificação de
unidades, compreensão das relações estabelecidas entre as unidades e das funções
discursivas associadas a elas no contexto); seja capaz de verificar as regularidades das
diferentes variedades do Português, reconhecendo os valores sociais nelas implicados
e, consequentemente, o preconceito contra as formas populares em oposição às formas
de grupos socialmente favorecidos (BRASIL, 1998, p. 52).

A linguagem bem compreendida instigará o leitor a explorar cada vez mais o cenário em que atua. As capacidades linguísticas, inseridas nos diversos contextos, propiciarão uma vasta bagagem cultural e comunicativa aos falantes. O objetivo é tornar o aluno protagonista e intérprete notável de sua própria linguagem, independente e reflexivo frente aos diversos meios de produção e escrita. Na visão de Lo Cascio (1978, p.41), a língua deve ser vista como instrumento único de comunicação: “a língua, além de ser um veículo de expressão e criatividade, é também instrumento de comunicação, é instrumento social". As vivências que cada falante porta em sua formação e prática devem ser concebidas como principal matéria de ensino e aprendizagem, pois a maneira como falamos e pautamos nossas práticas através do uso da língua correspondem a um aprimoramento perene da verdadeira identidade linguística.

A exploração orientada por novas concepções deve ser permeada pela exigência e pelo contexto em que a linguagem realiza sua função. A maturidade linguística deve ter uma visão que abrange e protagoniza a língua como uma identidade e uma ação do sujeito. A língua, como instrumento de identificação e portadora da mensagem humana, cogitará o sujeito em todos os âmbitos de sua atuação, formando assim um usuário capaz de estabelecer comunicação e permitir a comunicação na comunidade que o rodeia. 


\section{Considerações finais}

Considerando o que fora exposto neste artigo, pode-se concluir que o ensino de gramática exige uma avaliação institucional no que tange ao sentido atribuído a tais práticas direcionadas em vários meios, mas antes de mais nada uma avaliação pedagógica de cada mestre e falante. É uma atitude complexa, pois exige uma retomada de ideias já encrustadas no âmbito educacional e social, mas que estabelece reformulações nestes mesmos meios porque a insuficiência já é aparente e significativa.

Para tanto, o professor e o falante como um todo precisam conhecer novas habilidades e nortear-se por contextos até então pouco difundidos e reconhecidos. É preciso estar atento e pisar no chão da realidade em que a língua acontece e notar como ela é viva e exige escrever a história de cada idioma. Uma atitude de maturidade deve acontecer perante nossos ideais e gostos. A língua não pode ser lidada como algo particular ou intocável por grande parte das pessoas, mas como instrumento ao qual todos somos submetidos e precisamos manusear sem exageros e ressalvas.

Para Nicola (2007, p. 13), "as atuais teorias linguísticas e as propostas de ensino da Língua Portuguesa apontam para o texto como objeto central de ensino”. Nesta perspectiva, a autora acena para uma necessidade de centralizar a linguagem na sua produção e explicá-la em todas as suas categorias através daquilo que já nos foi dado e construído. A construção do entendimento da língua deve surgir em meio às necessidades e jamais em casos isolados e distantes da realidade do falante.

É notável que tais práticas apresentadas neste artigo apontam para uma realidade difícil do atual professor, pois este precisa dispor de tempo e leitura além daquele que já tem; mas utilizar-se dos meios e matérias de que dispõe já será suficiente para indicar ao aluno novas visões e práticas dentro e fora do ordinário escolar.

Como foi possível perceber, ligar as dimensões do estudo da língua e entendê-las como uma unicidade será o caminho para uma aprendizagem exata e atual. A análise gramatical, assim como a análise linguística, deve priorizar a exploração da língua e jamais separá-las. Percebe-se que através das propostas apresentadas, uma é extremamente necessária, a de se fazer ciência através da linguagem. Levar ao falante a capacidade de pensar e raciocinar sobre e com a Língua Portuguesa possibilitará um vasto campo de entendimento idiomático, artístico, comunicativo e midiático.

\section{Referências}


ANTUNES, Irandé Costa. Aula de português: encontro e interação. 8. ed. São Paulo: Parábola editorial, 2003.

Muito Além da Gramática: por um ensino de línguas sem pedras no caminho. Ed. Parábola, 2007

BECHARA, Evanildo. Ensino da Gramática: Opressão? Liberdade? São Paulo: Ática, 1985.

BRASIL. Secretaria de Educação Fundamental. Parâmetros Curriculares Nacionais: terceiro e quarto ciclos do ensino fundamental: língua portuguesa/ Secretaria de Educação Fundamental. Brasília: MEC/SEF. 1998.

CEGALLA, Domingos Paschoal. Novíssima gramática da língua portuguesa. 48.ed.rev.São Paulo: Companhia das Letras, 2008.

LO CASCIO, Vicenzo. Per um rinnovamento dela didattica dela lingua madre. In:

Prospettive sulla lingua madre. Roma, Instituto dela Enciclopedia Italiana, 1978.

NEVES, Maria Helena de Moura. Que Gramática usar na escola? Norma e uso na Língua Portuguesa. São Paulo: Contexto, 1990.

NICOLA, Rosane de Mello Santo. Prática Reflexiva e Ensino de Língua: uma Experiência de Estágio Supervisionado Alternativo. PUCPR/CPDE (Dom Bosco). Apresentação em mesa redonda do VII Congresso Nacional de Educação Saberes Docentes - novembro, 2007.

PERINI, M.A. A gramática descritiva do português. São Paulo: Ática, 2002.

Sofrendo a gramática. São Paulo: Ática, 2000.

RAMOS, Silva. Revista de Filologia Portuguesa. São Paulo. USP, 1924.

TRAVAGLIA, Luiz Carlos. Gramática e interação: uma proposta para o ensino da gramática no $1^{\circ}$ e $2^{\circ}$ grau. São Paulo: Cortez, 2002.

Gramática ensino plural. 5. ed. São Paulo: Cortez, 2011.

VIEIRA, S.R. Concordância verbal. In: VIEIRA. S. R; BRANDÃO. S. F. Ensino de Gramática: descrição e uso. 2. ed. São Paulo: Contexto, 2013.

VYGOTSKY, L.S. Pensamento e linguagem. São Paulo: Martins Fontes, 1989. 